\title{
Oxygen Transfer and Energy Dissipation by Nappe and Skimming Flow over Stepped Weir Structure
}

\author{
Jin-Hong Kim \\ Department of Civil and Environmental Engineering \\ Chung-Ang University \\ Seoul, Korea
}

Min-Jee Li

Department of Civil and Environmental Engineering Chung-Ang University, Seoul, Korea

\author{
Sun-Jung Kim \\ Department of Civil and Environmental Engineering \\ Chung-Ang University \\ Seoul, Korea
}

\begin{abstract}
Oxygen transfer and the energy dissipation by the flow types at the stepped weir structure were performed through hydraulic experiments. Nappe flow occurs at low flow rates and for relatively small step slope. Dominant features of an air pocket, nappe impact and subsequent hydraulic jump occurs. At larger flow rates, skimming flow occurs with formation of recirculating vortices. Transition flow showed simultaneous occurrence of skimming flow at upper steps and nappe flow at lower steps. Air entrainment occurs through free-falling nappe impact and subsequent hydraulic jump in the nappe flow, and occurs from the step edges in the skimming flow. Energy dissipation occurs through the jet impact and the subsequent hydraulic jump in the nappe flow and occurs through maintaining the recirculation vortices between step edges in the skimming flow regimes. The average values of the oxygen transfer are 0.45 in the nappe flow and 0.28 in the skimming flow, and the efficiencies of energy dissipation in the nappe flow and in the skimming flow are about $70 \sim 95(\%)$ and $60 \sim 90(\%)$, respectively. From these results, the stepped weir structure is found to be efficient for oxygen transfer and for energy dissipation.
\end{abstract}

Keywords- Oxygen transfer; Energy dissipation; Nappe flow; Skimming flow; Stepped weir

\section{INTRODUCTION}

Weir is installed to raise the water level for water intake or navigation. It makes deterioration of water quality by reducing the flow velocity and extending retention time of river flow. Thus, it is necessary to improve the water quality at the weir by oxygen transfer through air entrainment when the water flows over the weir.

Weir structures are useful for air entrainment by the stepped type of the overflow section. The flows over the stepped weir are characterized by the large amount of selfentrained air. Air entrainment by macro-roughness is efficient in water treatment because of the strong turbulent mixing. The macro roughness of the steps leads to an increase in the thickness of the turbulent boundary layer. Where the boundary layer reaches the free surface, air is entrained at the so-called inception point of air entrainment (Henry, 1985). They will be built along polluted and eutrophic streams to control the water quality through reoxygenation, denitrification and volatile organic component (VOC) removals (Henry, 1985).

Weir structures may also be useful for energy dissipation by the stepped type of the flow section. They are characterized by significant flow resistance and associated energy dissipation taking place on the steps (Chanson, Yasuda and Ohtsu, 2000). Thus, they are installed to protect the stream bed against scour since they are assuming a role for energy dissipation and for size reduction of retention basin or bottom protection, and for cutting costs (Fig .1).

This study presents the oxygen transfer through the air entrainment and the energy dissipation by the flow characteristics at the stepped weir structure. Hydraulic analysis on the oxygen transfer and the energy dissipation by the nappe flow and the skimming flow were performed through the hydraulic experiments.

\section{FLOW TYPES}

Flow over stepped weir structures are characterized by the two types : nappe flow and skimming flow shown in Fig .2. (Chanson, 1993). At low flow rates and for relatively large step height, nappe flow occurs. The water bounces from one step onto the next one. Dominant flow features include an enclosed air cavity, a free-falling jet, a nappe impact and a subsequent hydraulic jump. At larger flow rates and for relatively steep chute, skimming flow occurs. The flow skims over the step edges. The water flows down in a coherent stream where external edges determine a pseudo-bottom defined by the straight line that connects the edges of each step (Chanson, 1993). In a skimming flow, the free surface on the upper steps is clear and transparent. A turbulent boundary layer develops along the step edges. When the outer edge of the boundary layer reaches the free surface, free surface aeration takes place.

For intermediate flow rates, the flow exhibits strong splashing and droplet ejections at any position downstream of the inception point of free surface aeration : i.e. the transition flow regime. 

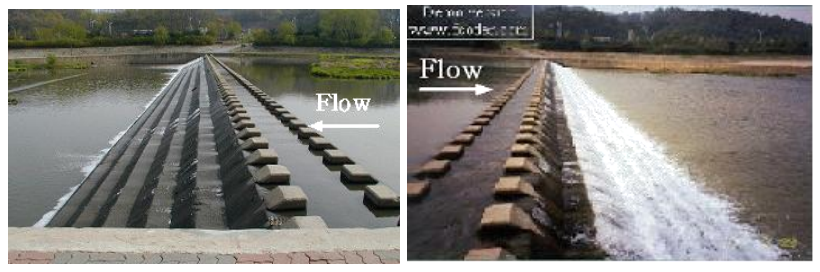

Figure 1. Stepped type of weir structure
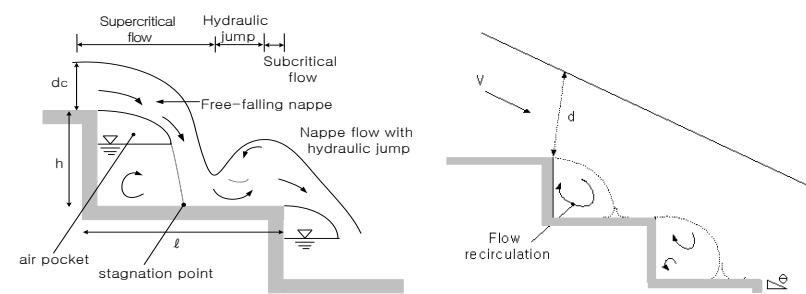

Figure 2. Sketch of nappe and skimming flow (Chanson, 1993)

The transition flow has a chaotic appearance with numerous drop ejections that are seen to reach heights of up to 3 to 8 times the step height (Chanson and Toombes, 2004). The transition between nappe and skimming flow is related to the flow rate, chute slope, step geometry and local flow properties. However this distinction does not seem to create well defined limits as for each geometric configuration (Fratino and Piccinni, 2000).

\section{OXYGEN TRANSFER AND ENERGY DISSIPATION}

Oxygen transfer through air entrainment occurs mainly from behind the trailing edge of the stepped weir structures due to flow separation (Kim, 2003). Air bubbles form and proceed to downward direction becoming larger in volume, and finally broken during proceeding upward. Dissolved oxygen is stored with breaking of the air bubbles, and this would give the good habitat condition

$$
\frac{\Delta H}{H_{\max }}=1-\frac{H_{\text {res }}}{H_{\max }}=1-\frac{\lambda+0.5 \lambda^{-2}}{H_{\text {weir }} / k+0.5} \lambda=\frac{\sqrt{2}}{1.06+\sqrt{h / k+1.5}}
$$

where $\Delta H$ is the head difference between upstream and downstream of the stepped weir structure, $H_{\max }$ is the maximum total head upstream of the structure, $H_{r e s}$ is the residual head downstream of the structure, $H_{\text {weir }}$ is the structure height, $k$ is the overflow depth at the crest of the structure, and $h$ is the step height.

Dissipation equation for the skimming flow regions is represented by (Fratino and Piccinni, 2000),

$$
\begin{gathered}
\frac{\Delta H}{H_{\max }}=1-\frac{\left[\frac{f}{8 \sin \boldsymbol{\alpha}}\right]^{1 / 3} \cos \boldsymbol{\alpha}+0.5\left[\frac{f}{8 \sin \boldsymbol{\alpha}}\right]^{-2 / 3}}{\frac{H_{\text {weir }}}{k}+1.5} \\
f=\frac{8 g \sin \boldsymbol{\alpha} d^{2}}{q^{2}} \cdot \frac{R}{4}
\end{gathered}
$$

where $\alpha$ is the slope of the stepped drop structure, $d$ is the uniform flow depth upstream of the structure, $R$ is the hydraulic radius, $q$ is the discharge per unit width, and $f$ is the friction factor representing aeration properties at the overflow sections. downstream of the stepped weir. Hydraulic jump makes the air entrainment more active.

The efficiency of the oxygen transfer $E$ is used for representing occurrence of air entrainment (Avery and Novak, 1978);

$$
E=\left(C_{d}-C_{u}\right) /\left(C_{s}-C_{u}\right)
$$

where $C_{d}$ and $C_{u}$ are contents of dissolved oxygen measured at downstream and upstream point, respectively, and $C_{s}$ is the saturated contents of the dissolved oxygen.

Since the oxygen transfer is affected by the water temperature, $E$ is substituted by $E_{20}$ (Gulliver et. al., 1990);

$$
\frac{\ln \left(1-E_{T}\right)}{\ln \left(1-E_{20}\right)}=1.0+\alpha(T-20)+\beta(T-20)^{2}
$$

where $E_{T}$ and $E_{20}$ are efficiencies of the oxygen transfer at temperature $T^{\circ} \mathrm{C}$ and the reference temperature $20^{\circ} \mathrm{C}$, respectively. $\alpha$ and $\beta$ are constants as $\alpha=0.02103{ }^{\circ} \mathrm{C}^{-1}$, $\beta=8.621 \times 10^{-5} \mathrm{C}^{-2}$.

The dissipation efficiency and the mechanisms that determine its effectiveness are defined using different evaluation processes for nappe and skimming flow regimes (Fratino and Piccinni, 2000). In the first case, energy dissipation is due to jet impact on the underlying water cushion and subsequent hydraulic jump. In contrast, most of the energy is dissipated in maintaining the recirculation vortices beneath the pseudo-bottom formed by the edges of the steps in the skimming flow regimes.

Dissipation equation for the nappe flow regions is represented by (Fratino and Piccinni, 2000),

\section{LABORATORY EXPERIMENTS}

Fig .3. shows the experimental arrangements. The typical model of the stepped weir structure made of waterproof plywood was installed in a recirculatory tilting flume of $0.6 \mathrm{~m}$ wide, $0.4 \mathrm{~m}$ deep and $15 \mathrm{~m}$ long. The sidewall of the flume was made of glass and a transparent scale was attached to the side wall to see the flow features well. A damper was laid at the upstream section of the flume to reduce the turbulence and to assure the hydraulic feed having negligible kinetic components. Water level was regulated by the down-stream adjustment weir. The discharge which was controlled by a valve in a feed-back loop could be measured with a v-notch at the upper tank.

The stepped weir model was $0.6 \mathrm{~m}$ wide and $0.31 \mathrm{~m}$ high. Five different slopes were selected $(1: 2.0,1: 1.7$, $1: 1.5,1: 1.2$ and 1:0.7). Hence, in case of the slope 1:2.0, the model was $0.6 \mathrm{~m}$ wide, $0.62 \mathrm{~m}$ long, $0.31 \mathrm{~m}$ high and on a slope of $30^{\circ}$. The number of steps was 6 , each step was $0.4 \mathrm{~m}$ wide, $0.10 \mathrm{~m}$ long and $0.05 \mathrm{~m}$ high.

Flow velocity was measured by using an electromagnetic current meter (model; MI-ECM4). To check the flow pattern, dye injection and a digital camera (model; Olympus c-5050z) with a strong light were used. 


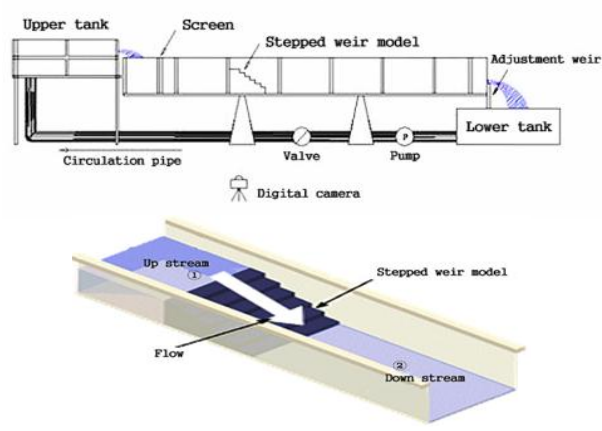

Figure 3. Experimental arrangement

Efficiencies of the oxygen transfer and the energy dissipation are estimated by measuring the dissolved oxygen and the total head at the upstream and downstream point of the structure, respectively. All the data are measured $5 \mathrm{~m}$ upstream and $10 \mathrm{~m}$ downstream of the structure for considering data consistency.

\section{RESULTS AND DISCUSSIONS}

Flow features of the nappe and skimming flow are shown in Fig . 4. Nappe flow occurs at low flow rates and for relatively small step slope. The flow is accelerated in the downstream direction until a deflected nappe took place. Dominant features of an air pocket, nappe impact and subsequent hydraulic jump occur apparently. The inception of free surface aeration took place at the first deflected nappe although some bubbles were trapped in cavities immediately upstream of the nappe take-off.

At larger flow rates, skimming flow occurs with formation of recirculating vortices between the main flow and the step corners. The flow direction of air-water mixture was almost parallel to the pseudo-bottom formed by the step edges although shapes of the recirculating vortices beneath the main flow alternate from step to step.

Transition between the nappe and skimming flow occurs. In this case, the skimming flow and the nappe flow occurs at upper steps and at lower steps, respectively. It does not have the quasi-smooth free surface appearance of skimming flow, nor the distinctive succession of free falling nappes observed in nappe flow. In transition flows down the step slope, the upstream flow is non-aerated. The free surface exhibited however an undular profile in phase with almost the same wave length as the stepped invert profile.

Air entrainment in the nappe flow and in the skimming flow is shown in Figs .5 and 6, respectively. In the nappe flow, free surface aeration was observed at both the upper and the lower nappes with additional air entrainment at the impact followed by jet breakup. Air entrainment occurs from the step edge, but most air is entrained through a free-falling nappe impact and hydraulic jump. Air pocket also has an important role to the air entrainment.

In the skimming flow, air entrainment occurs from the step edges. Downstream of the inception point, the flow is highly aerated at each and every step with very significant splashing.

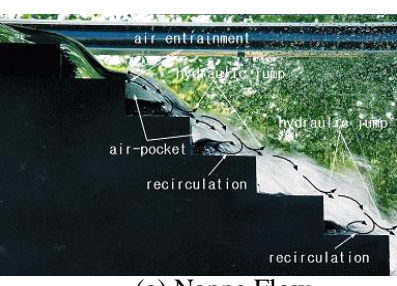

(a) Nappe Flow

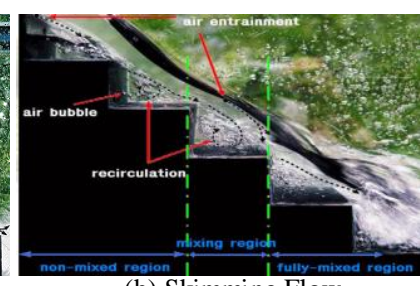

(b) Skimming Flow

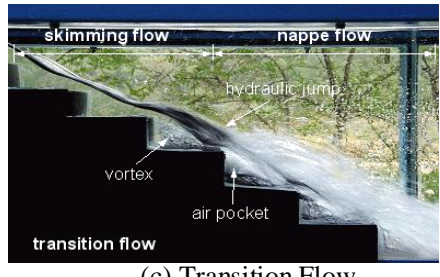

(c) Transition Flow

Figure 4. Measuring points at weir structure

Air entrainment was more active in the nappe flow than in the skimming flow, main reason of which is due to the nanne imnact and the subsequent hydraulic jump.
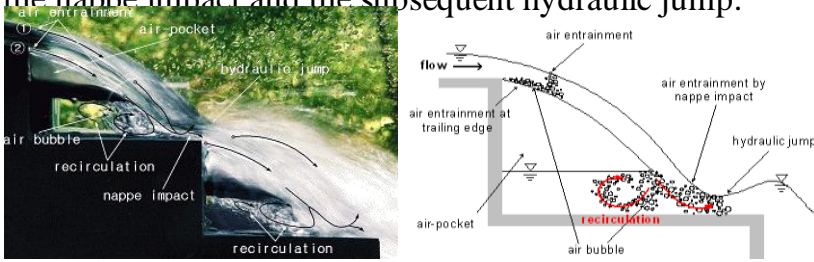

Figure 5. Air entrainment in the nappe flow
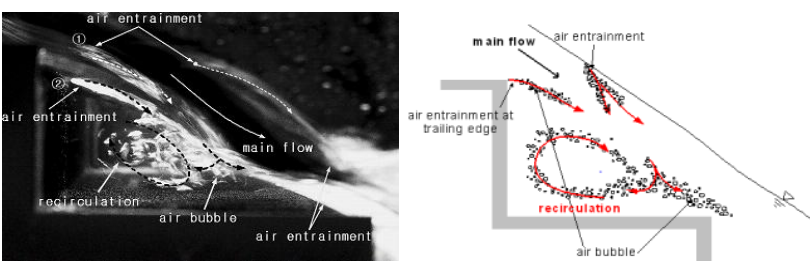

Figure 6. Air entrainment in the skimming flow

Fig .7 shows the relationship between the oxygen transfer and the flow velocity. Flow changes from a nappe flow to a skimming flow as the flow velocity increases. The transition between nappe and skimming flow was shown to occur at region of $\mathrm{v}=0.56-0.79(\mathrm{~m} / \mathrm{s})$. This is due to the undular profile of the free surface, acceleration above filled cavities and deceleration at nappe impact at that region suggested by Chanson and Toombes (2004).

Oxygen transfer becomes smaller and reaches to minimum at the region of a transition flow, but becomes larger in the region of skimming flow. It occurs more actively in the region of nappe flow than in the skimming flow. This is because the air entrainment is made mainly through a free-falling nappe impact, a hydraulic jump and an air pocket in the region of nappe flow, while they are not occurred in the region of the skimming flow. Oxygen transfer in the region of transition flow is not so high compared with nappe flow and skimming flow, since the flow in this region is not aerated but exhibits just an undular profile.

The average values of the oxygen transfer in the region of the nappe flow and in the region of the skimming flow are about 0.45 and 0.28 , respectively. It reveals that average value of the oxygen transfer at the 
riparian riffles is about 0.085 (Chanson, 1993), thus the stepped weir structure is found to be efficient for oxygen transfer and for treatment of water quality associated with substantial air entrainment.

Fig .8 shows the relationships between the energy dissipation and the ratio of overflow depth and step height in the region of nappe flow. Here, $h$ is the step height and $L$ is the step length. Hence, $h / L$ means the step slope.

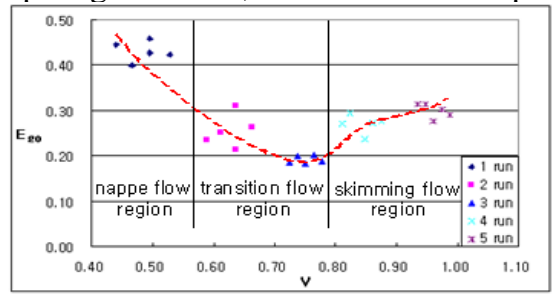

Figure 7. Oxygen transfer and flow velocity

All the other parameters are already explained in equation (3). The straight line is the theoretical results of equation (3).

Energy dissipation is proportional to the step height and is inversely proportional to the overflow depth, and is not proportional to the step slope, which means that it takes place mainly through the jet impact on the underlying water cushion and the subsequent hydraulic jump.

Experimental values except for those of $h / L=0.50$ showed the similar results to those of Fratino and Piccinni(2000) and the theoretical results, which is due to the longer interval of occurrence of the hydraulic jump.

Fig .9 shows the relationships between the energy dissipation and the ratio of structure height and overflow depth with parameters of slope angle in the region of skimming flow. Two curves are the theoretical results of equation (4) with $f$ equal to one and $\alpha$ equal to $60^{\circ}$ and $6^{\circ}$, respectively (Fratino and Piccinni, 2000).

Energy dissipation is related to the structure height and is not proportional to the step slope, which is the similar case in the nappe flow, since it occurs through maintaining the recirculation vortices between the step edges.

Theoretical results overestimate the experimental data although they show smaller differences when the step slope decreases. This seems to arise from the assumption of the constant value of friction factor, $f$, which depends on slope angle, overflow depth, flow discharge and hydraulic radius as is shown in equation (4).

In Figs .8 and 9, efficiencies of energy dissipation in the nappe flow and in the skimming flow are about 70 95(\%) and 60 90(\%), respectively. Energy dissipation in the nappe flow was still more active than in the skimming flow due to the jet impact on the underlying water cushion and the subsequent hydraulic jump. From these results, the stepped weir structure is also to be efficient for energy dissipation.

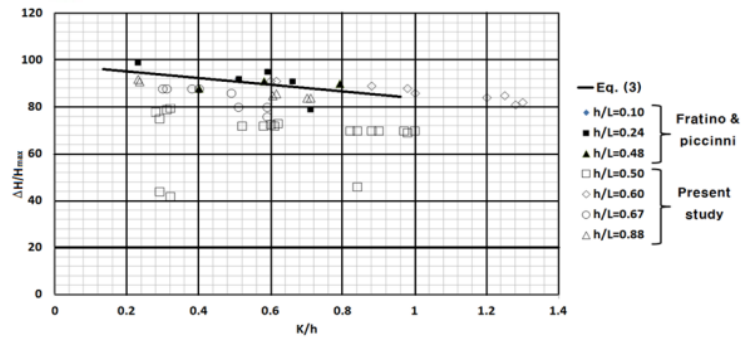

Figure 8. Energy dissipation in the nappe flow

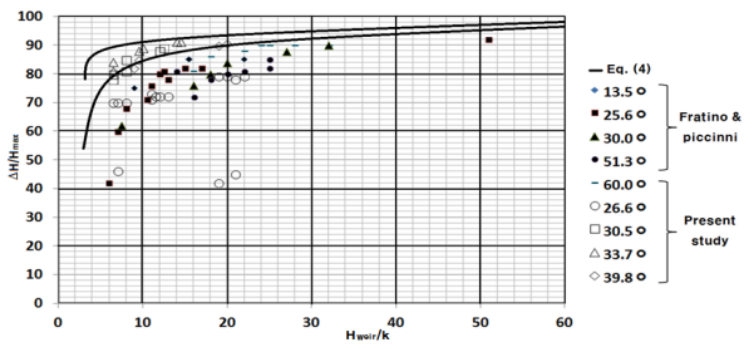

Figure 9. Energy dissipation in the skimming flow

\section{CONCLUSIONS}

In this study, oxygen transfer through the air entrainment and the energy dissipation by the flow types at the stepped weir structure were performed through the hydraulic experiments. Nappe flow occurs at low flow rates and for relatively small step slope. Dominant features of an air pocket, nappe impact and subsequent hydraulic jump occurs. At larger flow rates, skimming flow occurs with formation of recirculating vortices. As a transition flow, skimming flow at upper steps and nappe flow at lower steps occurs simultaneously. It does not have quasi-smooth free surface nor distinctive succession of free falling nappes. Air entrainment occurs from the step edge in the nappe flow, but most air is entrained through a free-falling nappe impact and hydraulic jump. In the skimming flow, air entrainment occurs from the step edges. Energy dissipation occurs through the jet impact on the underlying water cushion and the subsequent hydraulic jump in the nappe flow and occurs through maintaining the recirculation vortices between step edges in the skimming flow regimes. The average values of the oxygen transfer are 0.45 in the nappe flow and 0.28 in the skimming flow, which is higher than value at the riparian riffles, and the efficiencies of energy dissipation in the nappe flow and in the skimming flow are about 70 95(\%) and 60 90(\%), respectively. From these results, the stepped weir structure is found to be efficient for oxygen transfer and for energy dissipation.

\section{ACKNOWLEDGEMENT}

This research was supported by a grant (12-TI-C02) from Advanced Water Management Research Program funded by Ministry of Land, Infrastructure and Transport of Korean Government.

\section{REFERENCES}

[1] H. Chanson, "Self-aerated flows on chute and spillways." Journal of the Hydraulics Division, ASCE, Vol. 119, No. 2, 1993, pp. 220243. 
[2] H. Chanson and L. Toombes, "Hydraulics of stepped chutes: The transition flow." Journal of the Hydraulic Research, IAHR, Vol. 42, No. 1, 2004, pp. 43-54.

[3] H. Chanson, Y. Yasuda and I. Ohtsu, "Flow resistance in skimming flow: A critical review." Proceedings of the International Workshop on Hydraulics of Stepped Spillways, Zurich, Switzerland, Vol. 42, No. 1, 2000, pp. 43-54.

[4] J.H. Kim, "Water quality management by stepped overflow weir as a method of instream flow solution." Proceedings of the First International Conference on Solutions of Water Shortage and Instream Flow Problems in Asia. Incheon, Korea, 2003, pp. 24-36.
[5] J.S. Gulliver, J.R. Thene, and A.J. Rindels, "Indexing gas transfer in self-aerated flows." Journal of the Environmental Engineering, ASCE, Vol. 116, No. 3, 1990, pp. 503-523.

[6] S.T. Avery and P. Novak, "Oxygen transfer at hydraulic structures." Journal of the Hydraulics Division, ASCE, Vol. 104 No.11, 1978, pp. 1521-1540.

[7] T. Henry, Air-water flow in hydraulic structures. A Water Resources Technical Publication, Engineering Monograph No. 41, 1985, pp. 251-285.

[8] U. Fratino, and A.E. Piccinni, "Dissipation efficiency of stepped spillways" Proceedings of the $9^{\text {th }}$ International workshop on hydraulics of stepped spillway, Zurich, Switzerland, 2000, pp. 103110. 